\title{
Cellulose modulates biofilm formation by counteracting curli-mediated colonization of solid surfaces in Escherichia coli
}

\author{
Luciana Gualdi, ${ }^{1}$ Letizia Tagliabue, ${ }^{1}$ Stefano Bertagnoli, ${ }^{1}$ Teresa leranò, ${ }^{2}$ \\ Cristina De Castro $^{2}$ and Paolo Landini ${ }^{1}$ \\ ${ }^{1}$ Department of Biomolecular Sciences and Biotechnology, University of Milan, Via Celoria 26, \\ 20133 Milan, Italy \\ ${ }^{2}$ Department of Organic Chemistry and Biochemistry, University 'Federico II', Naples, Italy
}

Correspondence

Paolo Landini

paolo.landini@unimi.it

Received 29 February 2008

Revised 16 April 2008

Accepted 16 April 2008

\section{INTRODUCTION}

In Escherichia coli and Salmonella spp., curli fibres (also known as Tafi, thin aggregative fimbriae) are a major factor in adhesion to surfaces, cell aggregation and biofilm formation (Doran et al., 1993; Olsen et al., 1993; Hammar et al., 1995; Romling et al., 1998a). Curliencoding genes are located at a single genetic locus and clustered in the divergently oriented $\operatorname{csg} D E F G$ and $\operatorname{csg} B A$ operons (Arnqvist et al., 1994; Hammar et al., 1995). Transcription of the csgBA operon, encoding the structural components of curli fibres, strictly depends on the CsgD transcription regulator (Hammar et al., 1995). In addition, expression of both the $\operatorname{csg} D E F G$ and the $\operatorname{csgBA}$ operons takes place in response to a combination of environmental conditions, i.e. low growth temperature $\left(<32{ }^{\circ} \mathrm{C}\right)$, low osmolarity and slow growth (Olsen et al., 1993). These environmental signals are mediated at the gene expression level by a number of regulators, such as OmpR, H-NS,

\section{Abbreviation: $\mathrm{CV}$, crystal violet.}

Two supplementary figures are available with the online version of this paper.
CpxR, Crl, and the alternative sigma factor $\sigma^{\mathrm{s}}$, involved in csg gene expression regulation (Arnqvist et al., 1994; Romling et al., 1998b; Prigent-Combaret et al., 2001; Gerstel et al., 2003, Bougdour et al., 2004). However, mutations either in regulatory genes (Arnqvist et al., 1994; Vidal et al., 1998) or in the csgDEFG promoter (Romling et al., 1998b) can lead to loss of environmental control of curli expression in several enterobacterial isolates. Indeed, temperature-dependent regulation does not take place in several pathogenic E. coli strains, in which curli are expressed even at $37^{\circ} \mathrm{C}$ and appear to be involved in virulence-associated processes (Ben Nasr et al., 1996; Bian et al., 2000; Persson et al., 2003). In contrast, curli operons are silent in a large number of laboratory strains, as well as in some clinical and environmental isolates, despite the presence of functional csg genes (Romling et al., 1998a; Bokranz et al., 2005; Castonguay et al., 2006).

Besides its role as activator of the $\operatorname{csg} B A$ operon, CsgD regulates a number of genes involved in biofilm formation and production of cell-surface-associated structures (Latasa et al., 2005; Gibson et al., 2006), as well as genes involved in transport, metabolism and gene regulation (Chirwa \& 
Herrington, 2003; Brombacher et al., 2006). Arguably, however, the main function of $\mathrm{CsgD}$ besides curli regulation is activation of cellulose production, which results in the formation of a curli/cellulose extracellular matrix (Romling et al., 2000; Zogaj et al., 2001). CsgD stimulates cellulose production indirectly, by activating transcription of the adrA gene; in turn, the AdrA protein positively affects the enzymic activity of the cellulose biosynthetic machinery through its diguanylate cyclase activity, i.e. synthesis of the signal molecule cyclic di-GMP (c-di-GMP). c-di-GMP is a widely conserved bacterial second messenger that, in addition to biosynthesis of cellulose and other extracellular polysaccharides (Simm et al., 2004), is involved in various cellular processes, including biofilm formation (Hickman et al., 2005) and virulence (Tischler \& Camilli, 2005), and in morphological and physiological differentiation in Caulobacter crescentus (Paul et al., 2004).

Although cellulose was originally described as an additional determinant for biofilm formation in enterobacteria (Romling et al., 2000), its role as an adhesion factor is not straightforward (Wang et al., 2006). In this report, we show that cellulose negatively affects curli-mediated biofilm formation in a derivative of E. coli MG1655 constitutively expressing the $\mathrm{CsgD}$ protein, and we propose that cellulose production could be a determinant for resistance to environmental stresses rather than for biofilm formation.

\section{METHODS}

Bacterial strains and growth conditions. Strains and plasmids used in this study are listed in Table 1. Bacteria were grown in M9 minimal medium (Smith \& Levine, 1964) supplemented with $0.5 \%$ glucose and $2.5 \%$ Luria broth (M9Glu/sup) either at $30{ }^{\circ} \mathrm{C}$ or at $37^{\circ} \mathrm{C}$, as indicated. When needed, antibiotics were used at the following concentrations: ampicillin, $100 \mu \mathrm{g} \mathrm{ml}^{-1}$, chloramphenicol, $35 \mu \mathrm{g} \mathrm{ml}{ }^{-1}$; kanamycin, $50 \mu \mathrm{g} \mathrm{ml}^{-1}$. For growth on Congo-redsupplemented agar medium (CR medium), bacteria were inoculated in M9Glu/sup medium in a microtitre plate, and the cultures were spotted, using a replicator, on CR medium (1\% Casamino acids, $0.15 \%$ yeast extract, $0.005 \% \mathrm{MgSO}_{4}, 2 \%$ agar) to which $0.004 \%$ Congo red and $0.001 \%$ Coomassie blue were added after autoclaving. Both dyes were dissolved in $50 \%$ ethanol to a final concentration of $0.2 \%$ prior to addition to CR medium. Bacteria were grown for $20 \mathrm{~h}$ at either $30{ }^{\circ} \mathrm{C}$ or $37^{\circ} \mathrm{C}$; staining by Congo red was better detected after 1-2 days of additional incubation at $4{ }^{\circ} \mathrm{C}$.

Biofilm formation assays. Biofilm formation in microtitre plates was determined as described by Dorel et al. (1999). Bacterial cultures were grown in M9Glu/sup medium (Brombacher et al., 2006) either at $30{ }^{\circ} \mathrm{C}$ or at $37{ }^{\circ} \mathrm{C}$, for $18 \mathrm{~h}$, either in microtitre plates $(0.2 \mathrm{ml})$ or in $12 \mathrm{ml}$ glass tubes $(2.5 \mathrm{ml}$ cultures $)$ with vigorous shaking. The liquid culture was removed, and the cell density was determined by determining the $\mathrm{OD}_{600}$. Cells attached to the microtitre plates were washed with $0.1 \mathrm{M}$ phosphate buffer ( $\mathrm{pH} 7.0$ ), and then stained for 20 min with $1 \%$ crystal violet $(\mathrm{CV})$ in ethanol. The stained biofilms were thoroughly washed with water and dried. CV staining was visually assessed and the microtitre plates were scanned. For semiquantitative determination of biofilms, CV-stained cells were resuspended in either $0.2 \mathrm{ml}$ (for microtitre plates) or $2 \mathrm{ml}$ (for glass tubes) of $70 \%$ ethanol. The $A_{600}$ of the resuspended $\mathrm{CV}$ was

Table 1. Strains, plasmids, and primers used in this study

\begin{tabular}{|c|c|c|}
\hline Strain, plamid or primer & Relevant genotype or characteristics & Reference or source \\
\hline \multicolumn{3}{|l|}{ E. coli } \\
\hline MG1655 & Reference strain & Brombacher et al. (2006) \\
\hline PHL856 & MG1655 csgA:: uidA-kan & Prigent-Combaret et al. (2001) \\
\hline LG20 & $\begin{array}{l}\text { MG1655 crl:: 920cam; obtained by transduction } \\
\text { from LP468 (Pratt \& Silhavy, 1998) }\end{array}$ & This work \\
\hline LG26 & $\begin{array}{l}\text { MG1655 } \Delta b c s A: \text { : kan; obtained by P1vir transduction } \\
\text { from MG1655bcsA (gift from C. Beloin) }\end{array}$ & This work \\
\hline \multicolumn{3}{|l|}{ Plasmids } \\
\hline pT7-7 & $\begin{array}{l}\text { Control vector, ampicillin resistance, T7 RNA } \\
\text { polymerase-dependent promoter }\end{array}$ & $\begin{array}{l}\text { S. Tabor, Institute of Cancer Research, } \\
\text { London, UK }\end{array}$ \\
\hline pT7CsgD & $\begin{array}{l}\operatorname{csg} D \text { gene cloned into plasmid pT7-7 as a } 651 \text { bp } \\
\text { NdeI/Pst fragment }\end{array}$ & Prigent-Combaret et al. (2001) \\
\hline pTOPO & $\begin{array}{l}\text { Control vector allowing direct cloning of PCR } \\
\text { products, ampicillin and kanamycin resistance }\end{array}$ & Invitrogen \\
\hline pTOPOAdrA & adrA gene cloned as PCR product into pTOPO vector & This work \\
\hline Primers & Sequence & Utilization \\
\hline $\operatorname{csgB} B$ fw & CATAATTGGTCAAGCTGGGACTAA & RT-PCR experiments \\
\hline csgB_rev & GCAACAACCGCCAAAAGTTT & RT-PCR experiments \\
\hline adrA_rt_fw & GGCTGGGTCAGCTACCAG & RT-PCR experiments \\
\hline adrA_rt_rev & CGTCGGTTATACACGCCCG & RT-PCR experiments \\
\hline bcsA_rt_fw & GACGCTGGTGGCGCTG & RT-PCR experiments \\
\hline bcsA_rt_rev & GGGCCGCGAGATCACC & RT-PCR experiments \\
\hline adrA_fw & GCTCCGTCTCTATAATTTGGG & $a d r A$ cloning \\
\hline adrA_rev & ATCCTGATGACTTTCGCCGG & $a d r A$ cloning \\
\hline
\end{tabular}


determined and normalized to the $\mathrm{OD}_{600}$ of the corresponding grown cell density; this value is defined as 'adhesion unit'. In addition to CV staining, we measured the amount of bacterial cells by direct plating after vigorous resuspension of the biofilm; c.f.u. $\mathrm{ml}^{-1}$ counts always correlated with the amount of CV staining (data not shown).

To determine cell aggregation, $2 \mathrm{ml}$ cultures were grown overnight in $15 \mathrm{ml}$ Falcon tubes with vigorous shaking, then left standing at room temperature for $1 \mathrm{~h}$. Cell aggregation was determined by visual estimation of the cell sediment at the bottom of the Falcon tube.

Extracellular polysaccharide determination. Cellulose in the growth medium was determined by measuring the glucose reducing units produced after treatment with cellulase. Cultures $(50 \mathrm{ml})$ were grown overnight at either $30{ }^{\circ} \mathrm{C}$ or $37{ }^{\circ} \mathrm{C}$ in M9Glu/sup medium. The $\mathrm{OD}_{600}$ of the cultures was very similar for all strains and conditions used. Cells were pelleted by centrifugation, and the culture supernatants were lyophilized. Dried culture supernatants were dissolved in water at $100 \mathrm{mg} \mathrm{ml}^{-1}$ final concentration, and the resuspended culture supernatants were incubated with cellulase from Trichoderma reesei ATCC 26921 (5 mg ml $\mathrm{mg}^{-1}, 30 \mathrm{U} \mathrm{ml}^{-1}$; Sigma) in sodium acetate buffer ( $\mathrm{pH} \mathrm{5.0)}$ ) at $37^{\circ} \mathrm{C}$ for $16 \mathrm{~h}$. Glucose released from cellulose by cellulase digestion was estimated with the procedure described by Somogyi (1952) for the determination of reducing sugar units. As a standard for cellulose quantitative determination, we used a carboxymethylcellulose solution $\left(5 \mathrm{mg} \mathrm{ml}^{-1}\right)$ in sodium acetate buffer. For both culture supernatants and carboxymethylcellulose solution three different volumes $(5,15$ and $30 \mu \mathrm{l})$ were incubated with cellulase. The amounts of sugar released by carboxymethylcellulose degradation were used as calibration curve. For culture supernatants, the amounts of reducing sugars released by cellulase treatment were expressed as the percentage of total dry mass after lyophilization. In culture supernatants of the bcs mutant LG26 strain, used as negative control, the percentage of glucose released by cellulase treatment never exceeded $0.05 \%$ (Fig. 1b).

Gene expression determination by real-time PCR. For RNA isolation, strains were grown in M9Glu/sup either at $30{ }^{\circ} \mathrm{C}$ or at $37{ }^{\circ} \mathrm{C}$ overnight to $\mathrm{OD}_{600} 1.0$ (early stationary phase). Cells were harvested by centrifugation at $10000 \mathrm{~g}$ for $5 \mathrm{~min}$ at $4{ }^{\circ} \mathrm{C}$, and total RNA was extracted using the RNAeasy Mini kit (Qiagen). RNA samples were checked by agarose gel electrophoresis to assess lack of degradation, and quantified spectrophotometrically. Genomic DNA was removed by DNase I treatment. Reverse transcription was performed on $1 \mu \mathrm{g}$ total RNA, along with negative control samples incubated without reverse transcriptase. cDNA synthesis efficiency was verified by electrophoresis on agarose gel in comparison to negative controls. Real-time PCR was performed using the SYBR Green PCR master mix, and the results were determined with an iCycle iQ Real-Time detection system (Bio-Rad). Reaction mixtures $(25 \mu \mathrm{l})$ included $0.1 \mu \mathrm{g}$ cDNA and $300 \mathrm{nM}$ primers in the reaction buffer and enzyme supplied by the manufacturer. Primer sequences are listed in Table 1. All reactions were performed in triplicate, including negative control samples, which never showed significant threshold cycles. The relative transcript amounts were determined using $16 \mathrm{~S}$ rRNA as the reference gene: $C_{\mathrm{t}(\text { Gene of interest })}-C_{\mathrm{t}(16 \mathrm{~S})}=\Delta C_{\mathrm{t}}$ value.

Other methods. Bacteriophage P1vir transductions were carried out as described by Miller (1972). For overexpression of the AdrA protein, the $a d r A$ gene was amplified by PCR and the PCR product directly cloned into the pTOPO vector. The correct orientation of the $a d r A$ insertion (i.e. under the control of the lac promoter) was confirmed by digestion with $E c o$ RI/EcoRV, which gives two distinct digestion patterns depending on orientation of the $a d r A$ gene.

Desiccation experiments were performed as follows. Overnight cultures grown at $30{ }^{\circ} \mathrm{C}$ in $\mathrm{M} 9 \mathrm{Glu} /$ sup were diluted $1: 100$ in $\mathrm{H}_{2} \mathrm{O}$.
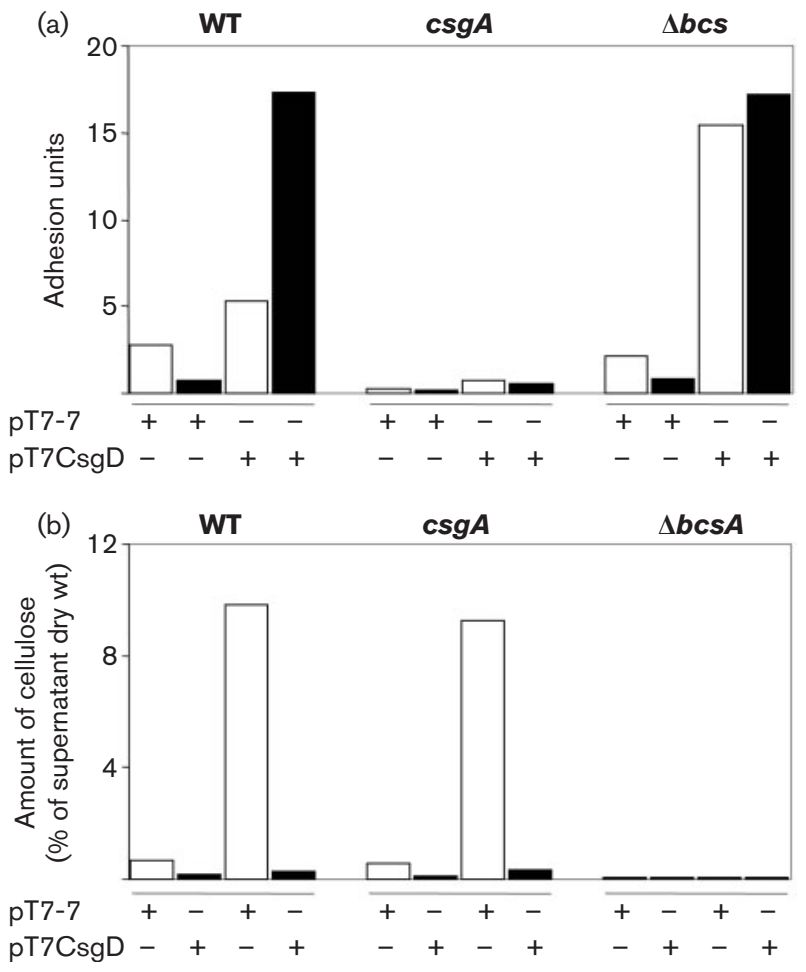

Fig. 1. (a) Biofilm formation on microtitre plates of $E$. coli MG1655 (wild-type, WT), PHL856 (csgA::kan) and LG26 ( $\triangle$ bcs::kan) transformed with either pT7-7 or pT7CsgD, grown either at $30{ }^{\circ} \mathrm{C}$ (white bars) or at $37{ }^{\circ} \mathrm{C}$ (black bars). Surfaceattached cells were quantified by spectrophotometric determination after CV staining and resuspension in ethanol, as described in Methods. Values are the mean of four independent experiments; standard deviation was always less than $15 \%$ of the mean. (b) Determination of cellulose production in E. coli MG1655 (WT), PHL856 (csgA::kan) and LG26 ( $\Delta b c s:: k a n)$ transformed with either pT7-7 or pT7CsgD, grown either at $30{ }^{\circ} \mathrm{C}$ (white bars) or at $37{ }^{\circ} \mathrm{C}$ (black bars). The values indicate the amount of cellulose as percentage of total dry weight of the culture supernatant after lyophilization. Values are the mean of two independent experiments which gave very similar results.

To determine bacterial concentration in the suspension before desiccation, $20 \mu \mathrm{l}$ was spotted on a glass slide, to which $80 \mu \mathrm{l} \mathrm{H} \mathrm{H}_{2} \mathrm{O}$ was added immediately. Serial dilutions $\left(10^{-2}\right.$ to $\left.10^{-5}\right)$ were plated on LB agar. Typical c.f.u. $\mathrm{ml}^{-1}$ values for the bacterial suspensions used in the desiccation experiments ranged between $10^{7}$ and $2.5 \times 10^{7}$. For the desiccation assay, $20 \mu \mathrm{l}$ of the bacterial suspension was spotted on a glass slide and allowed to air-dry at $30{ }^{\circ} \mathrm{C}$ for $1 \mathrm{~h}$, a time sufficient for full drying of the suspension drop. The dried suspension was resuspended in $100 \mu \mathrm{H} \mathrm{H}_{2} \mathrm{O}$, and serial dilutions $\left(10^{-1}\right.$ to $\left.10^{-4}\right)$ were plated on LB agar and incubated overnight at $37^{\circ} \mathrm{C}$. The percentage of cells surviving drying was calculated as recovered cells (c.f.u. $\mathrm{ml}^{-1}$ ) divided by the number of cells (c.f.u. $\mathrm{ml}^{-1}$ ) spotted on the glass slide. Efficient recovery of bacterial cells from the glass slide after exposure to dryness was verified by direct microscopic observation (at $100 \times$ magnification).

Curli subunit determination by SDS-PAGE was performed after formic acid solubilization of membrane-associated proteins. Samples 
$(50 \mathrm{ml})$ of cultures grown in M9Glu/sup at $30{ }^{\circ} \mathrm{C}$ for $18 \mathrm{~h}$ were centrifuged at $4000 \mathrm{~g}$ for $10 \mathrm{~min}$ at $4{ }^{\circ} \mathrm{C}$ and washed with $5 \mathrm{ml} 0.1 \mathrm{M}$ sodium phosphate buffer $\mathrm{pH}$ 7.0 (PB). Cells were resuspended in $1 \mathrm{ml} \mathrm{PB}$ with addition of $100 \mu \mathrm{g}$ lysozyme $\mathrm{ml}^{-1}$ and $1 \mathrm{mM}$ EDTA $\mathrm{pH} 8.0$ and incubated at room temperature for $10 \mathrm{~min}$. Cells were disintegrated using a French press and centrifuged at $30000 \mathrm{~g}$ for $30 \mathrm{~min}$. The pellet was dissolved in $1 \mathrm{ml} \mathrm{PB}$ and treated with formic acid as described by Collinson et al. (1991).

\section{RESULTS}

\section{Role of curli and cellulose in biofilm formation in E. coli MG1655}

The MG1655 laboratory strain of E. coli is proficient in curli production, as determined by its red phenotype on agar medium supplemented with Congo red stain (CR medium); the red phenotype of MG1655 on CR medium is totally abolished by inactivation of the $\operatorname{csg} A$ gene, encoding the major subunit of curli (see Supplementary Fig. S1, available with the online version of this paper). However, despite efficient curli production, MG1655 only shows limited ability to form biofilm on polypropylene microtitre plates (Fig. 1a), consistent with previous observations (Vidal et al., 1998; Prigent-Combaret et al., 2001; Gualdi et al., 2007). Inactivation of the csgA gene, but not of the cellulose biosynthetic bcsA gene, results in total loss of biofilm formation (Fig. 1a). Transformation of MG1655 with plasmid pT7CsgD greatly increases biofilm formation by MG1655, and this increase is totally dependent on curli production (Fig. 1a; Gualdi et al., 2007). In plasmid pT7CsgD, the $\operatorname{csg} D$ gene is under the control of a T7 RNA polymerase-dependent promoter, which is only weakly recognized by E. coli RNA polymerase (Brown \& Campbell, 1993). Presence of pT7CsgD results in a roughly 60 -fold increase of the $\operatorname{csg} D$ gene transcript (see Table 3).

In E. coli and Salmonella, expression of the csgBA genes, in turn leading to curli production and biofilm formation, is typically temperature-regulated and can take place at $\leqslant 30{ }^{\circ} \mathrm{C}$, but not at $37^{\circ} \mathrm{C}$ (Olsen et al., 1993; Romling et al., 1998a; Prigent-Combaret et al., 2001; Castonguay et al., 2006). However, transformation of MG1655 with pT7CsgD results in dramatically stronger biofilm formation at $37{ }^{\circ} \mathrm{C}$ compared to $30{ }^{\circ} \mathrm{C}$ (Fig. 1a). Biofilm formation experiments performed in glass tubes gave very similar results to those in microtitre plates, confirming the increased surface adhesion properties at $37^{\circ} \mathrm{C}$ of the MG1655/pT7CsgD strain (data not shown). Biofilm formation at $37^{\circ} \mathrm{C}$ is totally dependent on a functional $\operatorname{csg} A$ gene, suggesting that it is still mediated by curli production (Fig. 1a). However, csgBA operon transcription levels at $30{ }^{\circ} \mathrm{C}$ and $37{ }^{\circ} \mathrm{C}$ are comparable in MG1655/ pT7CsgD (Table 3), suggesting that increased biofilm formation at $37{ }^{\circ} \mathrm{C}$ in this strain is not mediated by a corresponding increase in curli production. These observations could suggest that curli fibres might synergize with an additional adhesion factor that is only expressed at $37{ }^{\circ} \mathrm{C}$. To identify such a factor, we analysed the membrane protein expression pattern (to verify temperature-dependent production of proteinaceous adhesion factors), and we determined production of extracellular polysaccharides (EPS) in MG1655/pT7CsgD, both at $30{ }^{\circ} \mathrm{C}$ and at $37{ }^{\circ} \mathrm{C}$. While the membrane protein pattern failed to show any significant difference in CsgD-dependent protein expression at either growth temperature (data not shown), analysis of EPS production pointed to a clear temperature dependence in the amount of cellulose production. Indeed, presence of plasmid $\mathrm{pT} 7 \mathrm{CsgD}$ resulted in a significant increase in the amount of cellulose found in the culture medium after cell removal by centrifugation (cellulose amounted to $9.8 \%$ of culture supernatant dry weight for MG1655/pT7CsgD versus $0.7 \%$ for MG1655 harbouring the pT7-7 control vector; Fig. 1b). However, pT7CsgDmediated increase in cellulose production was not detectable at $37{ }^{\circ} \mathrm{C}$ (Fig. 1b), i.e. in the conditions in which stimulation of biofilm formation by pT7CsgD is greater. Thus, cellulose production negatively correlates with surface adhesion in MG1655/pT7CsgD. Cellulose production was not affected by $\operatorname{csg} A$ inactivation, while, as expected, it was totally abolished in LG26, the bcsA mutant derivative of MG1655 (Fig. 1b). Chemical analysis identified glucose as the sole detectable sugar in the EPS recovered from the culture medium, indicating that cellulose is indeed the main component of EPS in the strains and conditions tested (data not shown).

To test the hypothesis that cellulose might act as a negative determinant for biofilm formation, we constructed an MG1655 derivative in which the bcsA gene, necessary for cellulose biosynthesis (Zogaj et al., 2001), is deleted. To this end, we transferred a $\Delta b c s A:$ : kan cassette to MG1655 by P1 vir phage transduction, obtaining strain LG26. In contrast to the effects of $\operatorname{csg} A$ inactivation, which totally abolishes biofilm formation by MG1655 even in the presence of plasmid pT7CsgD, deletion of the bcsA gene had very little effect on MG1655, but it strongly stimulated adhesion to microtitre plates at $30{ }^{\circ} \mathrm{C}$ in the presence of pT7CsgD, suggesting that cellulose can negatively affect curli-mediated biofilm formation (Fig. 1a). At $37^{\circ} \mathrm{C}$, deletion of the $b c s A$ gene had very little effect on biofilm formation, consistent with lack of cellulose production at this temperature.

To further test the role of cellulose in biofilm formation, we overexpressed the AdrA protein, which stimulates cellulose production via the c-di-GMP signal molecule (Simm et al., 2004). As shown in Fig. 2, AdrA overexpression resulted in a significant increase in surface adhesion by MG1655 at $30{ }^{\circ} \mathrm{C}$; this increase, however, was totally dependent on a functional $\operatorname{csg} A$ gene, thus suggesting that AdrA-induced adhesion properties are mediated by curli production, in agreement with recent results showing feedback regulation of the $\mathrm{CsgD}$ regulon by the AdrA protein (Kader et al., 2006). In contrast, deletion of the cellulose biosynthesis bcsA gene led to an increase in surface adhesion, consistent with cellulose being a negative determinant for biofilm formation. At $37{ }^{\circ} \mathrm{C}$, no detectable 


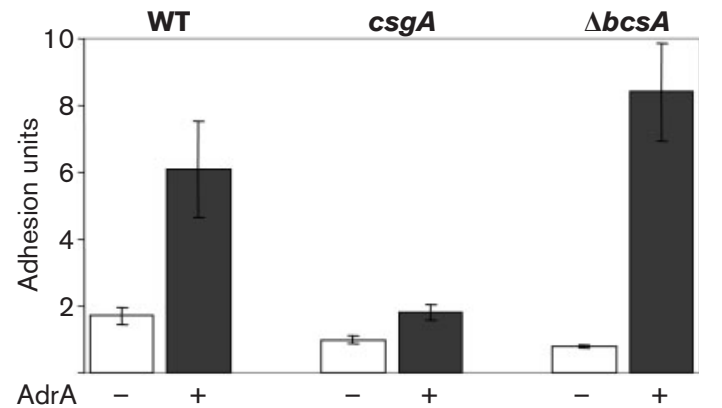

Fig. 2. Effect of AdrA overexpression on surface adhesion. Strains MG1655 (WT), PHL856 (csgA::kan) and LG26 ( $\Delta b c s:: k a n)$ were transformed either with the pTOPO vector (indicated as AdrA '-', white bars) or with pTOPOAdrA (AdrA '+', black bars) and grown overnight in M9Glu/sup at $30{ }^{\circ} \mathrm{C}$ prior to determination of surface adhesion by $\mathrm{CV}$ staining. Values were calculated as indicated in Methods and are the mean \pm SD of three independent experiments.

effects of AdrA overexpression on biofilm formation could be detected (data not shown).

Our results strongly suggest that, despite being produced in a co-ordinated fashion with curli fibres, cellulose counteracts curli-mediated biofilm formation on polypropylene (microtitre plates) and glass tubes. Thus, in order to understand the role of cellulose in E. coli MG1655, we performed bacterial cell aggregation (a biofilm-related process) tests and also tested resistance to desiccation. Several reports point to a role for cellulose in resistance to environmental stresses such as desiccation (Gibson et al., 2006) or resistance to chlorine treatment (Solano et al., 2002) in Salmonella species. As shown in Table 2, MG1655 grown in M9Glu/sup did not form any detectable cell

Table 2. Cell aggregation properties and resistance to desiccation

\begin{tabular}{|c|c|c|c|}
\hline \multirow[t]{2}{*}{ Strain } & \multicolumn{2}{|c|}{$\begin{array}{c}\text { Cell } \\
\text { aggregation }\end{array}$} & \multirow{2}{*}{$\begin{array}{l}\text { Cells surviving } \\
\text { exposure to } \\
\text { dry conditions } \\
(\%, \pm \mathrm{SD})^{*}\end{array}$} \\
\hline & $30{ }^{\circ} \mathrm{C}$ & $37^{\circ} \mathrm{C}$ & \\
\hline MG1655/pT7-7 & - & - & $1.8( \pm 0.14)$ \\
\hline MG1655/pT7CsgD & - & ++ & $7.6( \pm 0.25)$ \\
\hline PHL856 (csgA:: kan)/pT7-7 & - & - & $0.5( \pm 0.07)$ \\
\hline $\begin{array}{l}\text { PHL856 (csgA:: kan)/ } \\
\text { pT7CsgD }\end{array}$ & - & - & $3.5( \pm 0.17)$ \\
\hline LG26 $(\Delta b c s A:: k a n) / p T 7-7$ & - & - & $0.3( \pm 0.06)$ \\
\hline $\begin{array}{l}\text { LG26 }(\Delta b c s A:: k a n) / \\
\text { pT7CsgD }\end{array}$ & ++ & ++ & $1.6( \pm 0.11)$ \\
\hline
\end{tabular}

${ }^{*}$ Cells were incubated for $1 \mathrm{~h}$ at $30{ }^{\circ} \mathrm{C}$, and values (mean of three experiments) were determined as described in Methods.
Table 3. Relative expression of curli- and cellulose-related genes

\begin{tabular}{|lcccc|}
\hline & csgB & csgD & csgG & adrA \\
\hline MG1655/pT7-7 30 ${ }^{\circ} \mathrm{C}$ & $1^{*}$ & $1^{*}$ & $1^{*}$ & $1^{\star}$ \\
MG1655/pT7-7 37 ${ }^{\star} \mathrm{C}$ & 0.014 & 0.11 & 0.032 & 0.42 \\
MG1655/pT7CsgD 30 ${ }^{\circ} \mathrm{C}$ & 2430 & 60.8 & 15.3 & 337 \\
MG1655/pT7CsgD 37 ${ }^{\circ} \mathrm{C}$ & 1518 & 33.5 & 2.25 & 1.23 \\
\hline
\end{tabular}

${ }^{\star} \Delta C_{\mathrm{t}}$ between the gene of interest and the $16 \mathrm{~S}$ gene was arbitrarily set at 1 for MG1655/pT7-7 grown at $30{ }^{\circ} \mathrm{C}$ and expressed as relative values for other strains or growth conditions. Actual $\Delta C_{\mathrm{t}}$ values for MG1655/pT7-7 were: $\operatorname{csgB}, 12.1 ; \operatorname{csg} D, 9.2 ; \operatorname{csg} G, 12.4 ; \operatorname{adrA}, 16.5$.

aggregates; however, MG1655/pT7CsgD displayed a strong aggregative phenotype at $37^{\circ} \mathrm{C}$, but not at $30^{\circ} \mathrm{C}$. Deletion of the bcsA gene resulted in pT7CsgD-dependent cell aggregation even at $30{ }^{\circ} \mathrm{C}$, suggesting that cellulose plays a negative role in cell aggregation as well as in biofilm formation. In contrast, lack of cellulose biosynthetic genes resulted in a four- to fivefold decrease in sensitivity to desiccation (Table 2). Thus, our results would suggest that, in MG1655, cellulose function might be more related to resistance to environmental stresses rather than to biofilm formation and cell aggregation.

\section{Temperature-dependent regulation of curli- and cellulose-related genes}

Our results suggest that, despite constitutive expression of the CsgD protein in MG1655/pT7CsgD, cellulose biosynthesis does not take place at $37{ }^{\circ} \mathrm{C}$, in contrast to curli production (Fig. 1b). To better understand the mechanism of temperature regulation of both curli- and celluloserelated genes, we performed gene expression experiments on the cellulose-related $b c s A$ (cellulose biosynthesis) and $a d r A$ (regulator of cellulose production) genes, as well as on the $\operatorname{csg} g$ and $\operatorname{csg} B$ genes, which were chosen as representative of the two operons involved in curli biosynthesis ( $\operatorname{csg} D E F G$ and $\operatorname{csg} B A$ ), and on the $\operatorname{csg} D$ gene, to estimate the extent of its overexpression in MG1655/ pT7CsgD (Table 3). In order to evaluate the specific effects of CsgD overexpression, we compared MG1655/pT7CsgD to MG1655 transformed with the pT7-7 vector. Transcription of the bcsA gene was not affected by CsgD overexpression (data not shown), suggesting that expression of the bcs operon is independent of CsgD, as previously reported for Salmonella (Romling et al., 2000). At $30{ }^{\circ} \mathrm{C}, \mathrm{CsgD}$ overexpression from pT7CsgD results in increased transcription of both the curli-encoding $\operatorname{csg} B A$ operon and the $a d r A$ gene. In addition, CsgD can stimulate transcription from its own promoter, as indicated by $\operatorname{csg} G$ transcription levels (Table 3), in agreement with previous observations (Gualdi et al., 2007). In contrast, CsgD overexpression at $37{ }^{\circ} \mathrm{C}$ results in different levels of transcription activation at the promoters tested. Indeed, while $\mathrm{CsgD}$ can still activate the $\operatorname{csg} B$ promoter, indicating 
that its overexpression can bypass $\operatorname{csg} B$ temperature regulation, it fails to stimulate $a d r A$ expression (Table 3 ), suggesting tight temperature control at the $a d r A$ promoter. Finally, autoregulation of the $\operatorname{csg} D E F G$ operon by $\operatorname{CsgD}$ appears to still take place at $37^{\circ} \mathrm{C}$, although overall csgDEFG transcription levels are much lower at $37^{\circ} \mathrm{C}$ than at $30{ }^{\circ} \mathrm{C}$ even in MG1655/pT7CsgD (Table 3).

We also tested transcription levels of curli and cellulosebiosynthetic genes in LG20, a $\mathrm{crl}:$ : cam 920 derivative of MG1655, and we found that $\mathrm{Crl}$ is absolutely necessary for their transcription, at either growth temperature and regardless of the presence of pT7CsgD (data not shown).

\section{DISCUSSION}

The CsgD regulatory protein activates transcription of the $\operatorname{csg} B A$ operon and the adrA gene, thus leading to production of two extracellular structures: curli fibres and cellulose. Co-ordinated production of both curli and cellulose was initially proposed to be functional in cell adhesion and biofilm formation (Romling et al., 2000). However, a more recent report pointed to a negative role for cellulose in curli-mediated interaction of a commensal isolate of E. coli with the human epithelial cell line HT-29 (Wang et al., 2006). This observation would suggest that cellulose can inhibit, rather than stimulate, the function of curli as cell adhesion determinants. The results in our report are consistent with such a notion, strongly suggesting that cellulose overproduction in a $\operatorname{csg} D$-overexpressing derivative of the MG1655 laboratory strain of $E$. coli negatively affects both biofilm formation (Fig. 1) and cell aggregation (Table 2). Cellulose can stimulate, albeit weakly, biofilm formation in MG1655 (Fig. 1); however, in $a d r A$ - or csgD-overexpressing MG1655 derivatives, cellulose either fails to significantly affect or strongly impairs curli-dependent biofilm formation (Fig. 2). These results indicate that cellulose might act as a weak adhesion factor in strains poorly efficient in curli production; however, its production is detrimental for biofilm formation in bacterial strains that strongly produce curli (Figs 1 and 2 ), thus suggesting that cellulose modulates the cell's adhesion properties. Cellulose production does not inhibit curli-dependent biofilm formation through negative regulation of curli-encoding genes (data not shown), nor does it appear to prevent curli assembling on the bacterial cell surface, since similar amounts of formic-acid-soluble curli fibres were recovered from the cell membrane-associated protein fraction regardless of cellulose production (Supplementary Fig. S2). Thus, a possible mechanism for inhibition of curli-mediated adhesion by cellulose might be physical masking of curli fibres by excessive cellulose production, similar to the effect of other capsular polysaccharides on proteinaceous adhesion factors described by Schembri et al. (2004). Shielding of curli fibres by cellulose might be even more pronounced in cells growing on plates, as suggested by the observation that cellulose production in the MG1655/pT7CsgD at $30{ }^{\circ} \mathrm{C}$ leads to partial loss of red phenotype on Congo-redsupplemented medium (Supplementary Fig. S1).

In contrast to the effect on biofilm formation, cellulose appears to play a role in protection against environmental stresses such as desiccation (Table 2), in agreement with previous observations in Salmonella spp. (White et al., 2006), and as also reported for other capsular polysaccharides and extracellular structures (Hagiwara et al., 2003; Gibson et al., 2006). Interestingly, even csgA inactivation results in a decreased resistance to desiccation (Table 2), suggesting that the curli/cellulose network might confer better protection against desiccation than cellulose alone. While our results confirm the role of cellulose in resistance to environmental stresses, they suggest that cellulose acts as a negative determinant for biofilm formation, in contrast to previous observations in Salmonella (Romling et al., 2000; Solano et al., 2002). Such discrepancies could depend on the pattern of adhesion factors produced by different bacterial species: indeed, it is possible that cellulose, rather than acting directly as a biofilm determinant, might modulate either expression or surface exposure of adhesion factors, thus affecting adhesion properties in a speciesspecific, and even strain-specific, fashion. Finally, it must be stressed that we only tested one experimental system for biofilm formation, and we cannot rule out that cellulose might positively contribute to biofilm formation in other conditions or model systems.

Interestingly, in contrast to the curli-related csg operons, the $a d r A$ gene, encoding a diguanylate cyclase regulating cellulose production, is not activated by constitutive expression of $\mathrm{CsgD}$ at $37^{\circ} \mathrm{C}$ (Table 3), thus suggesting tighter temperature-dependent control of its transcription. Similar to $\operatorname{csg} B A, a d r A$ requires a functional $\mathrm{crl}$ gene for its expression (data not shown), consistent with previous observations in Salmonella enterica (Robbe-Saule et al., 2006).

Our results suggest that, when expressed at $37{ }^{\circ} \mathrm{C}, \mathrm{CsgD}$ would activate transcription of the curli-encoding $\operatorname{csg} B A$ operon, but not of the cellulose biosynthetic adrA and $b c s$ genes. Although in our experiments we used a strain in which $\mathrm{CsgD}$ is expressed ectopically, i.e. from plasmid pT7CsgD, our results are consistent with previous observations on E. coli isolates expressing curli-encoding genes in a temperature-independent manner. Indeed, in enterohaemorrhagic strains of E. coli (Uhlich et al., 2001, 2006), mutations in the $\operatorname{csg} D E F G$ promoter leading to increased CsgD expression result in increased expression of curli-encoding genes at $37^{\circ} \mathrm{C}$, but fail to stimulate cellulose production. However, ability to produce either curli or cellulose, or both, at $37{ }^{\circ} \mathrm{C}$ is likely to be influenced by specific genetic backgrounds. Indeed, in a survey of E. coli isolates from humans, it was reported that, when grown at $37{ }^{\circ} \mathrm{C}, 21 \%$ of the isolates were able to express both curli and cellulose, while $23 \%$ were only able to produce curli (Bokranz et al., 2005). Thus, mutations resulting in sole expression of curli, but not cellulose, at $37{ }^{\circ} \mathrm{C}$, are rather 
common in E. coli strains isolated from humans. These results seem to suggest that mutations leading to increased curli production at $37{ }^{\circ} \mathrm{C}$ might be well tolerated, or even advantageous for some E. coli isolates, possibly due to the role of curli in internalization of bacteria by eukaryotic cells (Gophna et al., 2001). In contrast, mutations leading to production of only cellulose, but not curli, at $37^{\circ} \mathrm{C}$ are highly unusual, perhaps suggesting that they might be unfavourable in the mammalian host. Finally, inactivation of the $\operatorname{csg} D$ gene by insertion sequences is a common trait of Shigella spp., and loss of expression of $c s g D$-dependent genes is considered a pathoadaptive mutation (Sakellaris et al., 2000). These different genetic and mutational patterns leading to different expression patterns of $\operatorname{csg} D$ dependent genes at $37^{\circ} \mathrm{C}$ probably reflect their highly complex regulation, as well as the multifaceted role played by curli and cellulose in the interaction between bacterial cells and the host environment.

\section{ACKNOWLEDGEMENTS}

We would like to thank Cristophe Beloin for the gift of the $\Delta b c s$ strain and Davide Antoniani for technical help. This work was supported by the European Space Agency MAP project number AO-LS-99-MAPLSS018.

\section{REFERENCES}

Arnqvist, A., Olsen, A. \& Normark, S. (1994). Sigma S-dependent growth-phase induction of the csgBA promoter in Escherichia coli can be achieved in vivo by sigma 70 in the absence of the nucleoidassociated protein H-NS. Mol Microbiol 13, 1021-1032.

Ben Nasr, A., Olsen, A., Sjobring, U., Muller-Esterl, W. \& Bjorck, L. (1996). Assembly of human contact phase proteins and release of bradykinin at the surface of curli-expressing Escherichia coli. Mol Microbiol 20, 927-935.

Bian, Z., Brauner, A., Li, Y. \& Normark, S. (2000). Expression of and cytokine activation by Escherichia coli curli fibers in human sepsis. J Infect Dis 181, 602-612.

Bokranz, W., Wang, X., Tschape, H. \& Romling, U. (2005). Expression of cellulose and curli fimbriae by Escherichia coli isolated from the gastrointestinal tract. J Med Microbiol 54, 1171-1182.

Bougdour, A., Lelong, C. \& Geiselmann, J. (2004). Crl, a low temperature induced protein in Escherichia coli that binds directly to the stationary phase sigma subunit of RNA polymerase. J Biol Chem 279, 19540-19550.

Brombacher, E., Baratto, A., Dorel, C. \& Landini, P. (2006). Gene expression regulation by the Curli activator CsgD protein: modulation of cellulose biosynthesis and control of negative determinants for microbial adhesion. J Bacteriol 188, 2027-2037.

Brown, W. C. \& Campbell, J. L. (1993). A new cloning vector and expression strategy for genes encoding proteins toxic to Escherichia coli. Gene 127, 99-103.

Castonguay, M. H., van der Schaaf, S., Koester, W., Krooneman, J., van der Meer, W., Harmsen, H. \& Landini, P. (2006). Biofilm formation by Escherichia coli is stimulated by synergistic interactions and co-adhesion mechanisms with adherence-proficient bacteria. Res Microbiol 157, 471-478.
Chirwa, N. T. \& Herrington, M. B. (2003). CsgD, a regulator of curli and cellulose synthesis, also regulates serine hydroxymethyltransferase synthesis in Escherichia coli K-12. Microbiology 149, 525-535.

Collinson, S. K., Emödy, L., Müller, K.-H., Trust, T. J. \& Kay, W. W. (1991). Purification and characterization of thin, aggregative fimbriae from Salmonella enteritidis. J Bacteriol 173, 4773-4781.

Doran, J. L., Collinson, K., Burian, J., Sarlos, G., Todd, E. C. D., Munro, C. K., Kay, C. M., Banser, P. A., Peterkin, P. I. \& Kay, W. W. (1993). DNA-based diagnostic tests for Salmonella species targeting agfA, the structural gene for thin, aggregative fimbriae. J Clin Microbiol 31, 2263-2273.

Dorel, C., Vidal, O., Prigent-Combaret, C., Vallet, I. \& Lejeune, P. (1999). Involvement of the Cpx signal transduction pathway of E. coli in biofilm formation. FEMS Microbiol Lett 178, 169-175.

Gerstel, U., Park, C. \& Romling, U. (2003). Complex regulation of $c s g D$ promoter activity by global regulatory proteins. Mol Microbiol 49, 639-654.

Gibson, D. L., White, A. P., Snyder, S. D., Martin, S., Heiss, C., Azadi, P., Surette, M. \& Kay, W. W. (2006). Salmonella produces an Oantigen capsule regulated by AgfD and important for environmental persistence. J Bacteriol 188, 7722-7730.

Gophna, U., Barlev, M., Seijffers, R., Oelschlager, T. A., Hacker, J. \& Ron, E. Z. (2001). Curli fibers mediate internalization of Escherichia coli by eukaryotic cells. Infect Immun 69, 2659-2665.

Gualdi, L., Tagliabue, L. \& Landini, P. (2007). A biofilm formationgene expression relay system in Escherichia coli: modulation of $\sigma^{\mathrm{S}}$ dependent gene expression by the $\mathrm{CsgD}$ regulatory protein via $\sigma^{\mathrm{S}}$ protein stabilization. J Bacteriol 189, 8034-8043.

Hagiwara, D., Sugiura, M., Oshima, T., Mori, H., Aiba, H., Yamashino, T. \& Mizuno, T. (2003). Genome-wide analyses revealing a signaling network of the RcsC-YojN-RcsB phosphorelay system in Escherichia coli. J Bacteriol 185, 5735-5746.

Hammar, M., Arnqvist, A., Bian, Z., Olsen, A. \& Normark, S. (1995). Expression of two csg operons is required for production of fibronectin- and Congo red-binding curli polymers in Escherichia coli K-12. Mol Microbiol 18, 661-670.

Hickman, J. W., Tifrea, D. F. \& Harwood, C. S. (2005). A chemosensory system that regulates biofilm formation through modulation of cyclic diguanylate levels. Proc Natl Acad Sci U S A 102, 14422-14427.

Kader, A., Simm, R., Gerstel, U., Morr, M. \& Romling, U. (2006). Hierarchical involvement of various GGDEF domain proteins in rdar morphotype development of Salmonella enterica serovar Typhimurium. Mol Microbiol 60, 602-616.

Latasa, C., Roux, A., Toledo-Arana, A., Ghigo, J. M., Gamazo, C., Penades, J. R. \& Lasa, I. (2005). BapA, a large secreted protein required for biofilm formation and host colonization of Salmonella enterica serovar Enteritidis. Mol Microbiol 58, 1322-1339.

Miller, J. H. (editor) (1972). Experiments in Molecular Genetics. Cold Spring Harbor, NY: Cold Spring Harbor Laboratory.

Olsen, A., Arnqvist, A., Hammar, M. \& Normark, S. (1993). Environmental regulation of curli production in Escherichia coli. Infect Agents Dis 2, 272-274.

Paul, R., Weiser, S., Amiot, N. C., Chan, C., Schirmer, T., Giese, B. \& Jenal, U. (2004). Cell cycle-dependent dynamic localization of a bacterial response regulator with a novel di-guanylate cyclase output domain. Genes Dev 18, 715-727.

Persson, K., Russell, W., Morgelin, M. \& Herwald, H. (2003). The conversion of fibrinogen to fibrin at the surface of curliated Escherichia coli bacteria leads to the generation of proinflammatory fibrinopeptides. J Biol Chem 278, 31884-31890. 
Pratt, L. A. \& Silhavy, T. J. (1998). Crl stimulates RpoS activity during stationary phase. Mol Microbiol 29, 1225-1236.

Prigent-Combaret, C., Brombacher, E., Vidal, O., Ambert, A., Lejeune, P., Landini, P. \& Dorel, C. (2001). Complex regulatory network controls initial adhesion and biofilm formation in Escherichia coli via regulation of the csgD gene. J Bacteriol 183, 7213-7223.

Robbe-Saule, V., Jaumouille, V., Prevost, M. C., Guadagnini, S., Talhouarne, C., Mathout, H., Kolb, A. \& Norel, F. (2006). Crl activates transcription initiation of RpoS-regulated genes involved in the multicellular behavior of Salmonella enterica serovar Typhimurium. J Bacteriol 188, 3983-3994.

Romling, U., Bian, Z., Hammar, M., Sierralta, W. D. \& Normark, S. (1998a). Curli fibers are highly conserved between Salmonella typhimurium and Escherichia coli with respect to operon structure and regulation. $J$ Bacteriol 180, 722-731.

Romling, U., Sierralta, W. D., Eriksson, K. \& Normark, S. (1998b). Multicellular and aggregative behaviour of Salmonella typhimurium strains is controlled by mutations in the agfD promoter. Mol Microbiol 28, 249-264.

Romling, U., Rohde, M., Olsen, A., Normark, S. \& Reinkoster, J. (2000). AgfD, the checkpoint of multicellular and aggregative behaviour in Salmonella typhimurium regulates at least two independent pathways. Mol Microbiol 36, 10-23.

Sakellaris, H., Hannink, N. K., Rajakumar, K., Bulach, D., Hunt, M., Sasakawa, C. \& Adler, B. (2000). Curli loci of Shigella spp. Infect Immun 68, 3780-3783.

Schembri, M. A., Dalsgaard, D. \& Klemm, P. (2004). Capsule shields the function of short bacterial adhesins. J Bacteriol 186, 1249-1257.

Simm, R., Morr, M., Kader, A., Nimtz, M. \& Romling, U. (2004). GGDEF and EAL domains inversely regulate cyclic di-GMP levels and transition from sessility to motility. Mol Microbiol 53, 1123-1134.

Smith, H. O. \& Levine, M. (1964). Two sequential repressions of DNA synthesis in the establishment of lysogeny by phage P22 and its mutants. Proc Natl Acad Sci U S A 52, 356-363.
Solano, C., Garcia, B., Valle, J., Berasain, C., Ghigo, J. M., Gamazo, C. \& Lasa, I. (2002). Genetic analysis of Salmonella enteritidis biofilm formation: critical role of cellulose. Mol Microbiol 43, 793-808.

Somogyi, M. (1952). Notes on sugar determination. J Biol Chem 195, 19-23.

Tischler, A. D. \& Camilli, A. (2005). Cyclic diguanylate regulates Vibrio cholerae virulence gene expression. Infect Immun 73, 5873-5882.

Uhlich, G. A., Keen, J. E. \& Elder, R. O. (2001). Mutations in the $c s g D$ promoter associated with variations in curli expression in certain strains of Escherichia coli O157 : H7. Appl Environ Microbiol 67, 23672370.

Uhlich, G. A., Cooke, P. H. \& Solomon, E. B. (2006). Analyses of the red-dry-rough phenotype of an Escherichia coli O157:H7 strain and its role in biofilm formation and resistance to antibacterial agents. Appl Environ Microbiol 72, 2564-2572.

Vidal, O., Longin, R., Prigent-Combaret, C., Dorel, C., Hooreman, M. \& Lejeune, P. (1998). Isolation of an Escherichia coli K-12 mutant strain able to form biofilms on inert surfaces: involvement of a new $o m p R$ allele that increases curli expression. J Bacteriol 180, 2442-2449.

Wang, X., Rochon, M., Lamprokostopoulou, A., Lunsdorf, H., Nimitz, M. \& Romling, U. (2006). Impact of biofilm matrix components on interaction of commensal Escherichia coli with the gastrointestinal cell line HT-29. Cell Mol Life Sci 63, 2352-2363.

White, A. P., Gibson, D. L., Kim, W., Kay, W. W. \& Surette, M. G. (2006). Thin aggregative fimbriae and cellulose enhance long-term survival and persistence of Salmonella. J Bacteriol 188, 3219-3227.

Zogaj, X., Nimtz, M., Rohde, M., Bokranz, W. \& Romling, U. (2001). The multicellular morphotypes of Salmonella typhimurium and Escherichia coli produce cellulose as the second component of the extracellular matrix. Mol Microbiol 39, 1452-1463.

Edited by: D. L. Gally 